Original Research Paper

\title{
Prevalence of HSV1 and HSV2 among HIV Patients in Northern South Africa as Determined by Real Time PCR in Urine Samples
}

\author{
Amidou Samie, Hlayisani Preclude Mnisi and Mary Noluthando Ramantswana \\ Department of Microbiology, Molecular Parasitology and Opportunistic Infection Program, \\ University of Venda, Private bag X5050, Thohoyandou 0950, South Africa
}

\author{
Article history \\ Received: 05-01-2017 \\ Revised: 12-01-2017 \\ Accepted: 14-03-2017 \\ Corresponding Author: \\ Amidou Samie \\ Department of Microbiology, \\ Molecular Parasitology and \\ Opportunistic Infections \\ Program, School of \\ Mathematical and Natural \\ Sciences, University of Venda, \\ Private Bag X5050, \\ Thohoyandou 0950, South \\ Africa \\ Tel: +27159628186 \\ Fax: +27159628648 \\ Email: samieamidou@yahoo.com \\ samie.amidou@univen.ac.za
}

\begin{abstract}
The present study determined the prevalence of HSV-1 and 2 among HIV patients in Northern South Africa and identified potential risk factors. Urine samples were collected from patients attending different HIV clinics in Limpopo Province. Total genomic DNA was isolated from these samples using GenElute Blood Genomic DNA Kit and real time PCR protocols were used for the detection of HSV1 and HSV2. Demographic, clinical and socioeconomic data were collected using a structured questionnaire. The overall prevalence of HSV1 was $48.5 \%$ while that of HSV2 was $10.8 \%$ from a total of 308 samples. The prevalence of HSV1 was higher among females while that of HSV2 did not vary between males and females. Patients on zidovudine had a much lower prevalence. Patients who had TB $\left(\chi^{2}=9.128 ; p=0.003\right)$, seemed to have a much higher susceptibility to HSV-1.However, this was not the case with HSV2. CD4 count and viral load did not seem to have any impact of the occurrence of HSV among these patients. Urine samples appear to be a useful alternative for the detection of the HSV. Generally, history of TB, usage of certain ARVs and early age of sexual debut appeared to be important risk factors for HSV.
\end{abstract}

Keywords: Herpes Simplex Virus, HIV, Opportunistic Infection, South Africa

\section{Introduction}

Herpes Simplex Virus (HSV) type one and two are both major causes of genital and oral herpes (Swenson et al., 2016). Most genital ulcers are caused by HSV-2 although in recent years there has been an increase in infection caused by HSV-1 (Garland and Steben, 2015). HSV can cause death to new born, but fortunately such cases are uncommon. Important feature of these viruses is that, they enter the ganglion and cause latent infection (Rezaei-Chaparpordi et al., 2012). Infection is acquired mostly through sexual activity (oral, virginal or anal). For infection to occur, HSV must come into contact with mucosal surfaces (Whitley and Roizman, 2001). HSV both type one and two manifest with mild symptoms or are even asymptomatic, which increases the rate of transmission (Rodrigues et al., 2013).

The prevalence of HSV-1 and 2 differs widely between and within countries (Looker et al., 2015). Daily suppressive therapy with acyclovir, famciclovir and valacyclovir decreases HSV shedding dramatically and thereby decreases transmission along with decreased HIV viral loads (Nag et al., 2015). Antiretroviral (ARV) treatment used for the management of Human Immunodeficiency Virus (HIV) infections has been initiated in South Africa since 2004. However, no studies have estimated the impact of ARV treatment in the Northern part of the country on the occurrence of other opportunistic infections such as HSV-1 and HSV-2. Therefore regular surveys on the epidemiology of Herpes Simplex viruses are useful.

Real-time PCR has been used for the detection of HSV. The speed and sensitivity of the real-time Polymerase Chain Reaction (PCR) have made it a popular method for the detection of microbiological agents in both research and clinical specimens (Filén et al., 2004). For the detection and genotyping of herpes simplex virus in clinical specimens, real-time PCR has been proven to be faster, more sensitive and safer than earlier methods which included isolation of the virus in cell culture followed by immune fluorescence 
microscopy. While PCR-based assays for HSV detection possess clear advantages over these earlier techniques, certain aspects of the PCR method remain onerous (Pandori et al., 2006). Information on the prevalence of HSV-2 and HSV-1 is essential to optimize genital herpes control strategies. However, there is limited data on the distribution and risk factors of HSV transmission in the northern regions of South Africa.

Most studies conducted on the prevalence of HSV1 and 2, have used serum samples (Wang et al., 2016; Weiss et al., 2016). Although this can show that the study subjects have been in contact with the virus, it does not determine if these individuals are currently carrying the virus and are therefore capable of transmitting it. The detection of the virus using molecular methods such as real time PCR will identify the persons actually carrying the virus therefore providing important epidemiological data on the actual carriage rate of $\mathrm{HSV}-1$ and 2 in the concerned population. In fact, a cross sectional study in the Gambia showed that $46 \%$ of the tested population were positive for HSV-2 antibody. However, none of them were actually shedding the virus (Aryee et al., 2005). A study conducted in the Eastern Cape Province, South Africa showed an HSV sero-prevalence of $27.6 \%$ (Jewkes et al., 2008). Therefore, prevalence studies are critical to understand the pattern and distribution of infection within populations. The present study aimed to determine the prevalence of HSV-1/2 infection among HIV patients attending different hospitals in Vhembe district, Limpopo province using real-time PCR in urine samples.

\section{Materials and Methods}

\section{Patient's Recruitment and Data Collection}

Ethical clearance was obtained from the Health and Ethics committee of the University of Venda and the Limpopo Department of Health, in Polokwane. Study participants were HIV positive confirmed patients who were attending the different hospitals and Health care centres for HIV care including counselling, ARV administration or general care.

The present study was a cross sectional descriptive survey study of opportunistic infections among HIV patients in Northern South Africa. Patients were recruited randomly from different hospitals and health care centres in the region including Tshakuma health care centre, Tshilidzini hospital, Elim hospital, Donald Fraser hospital and University of Venda clinic. The objectives and procedures of the study were clearly explained to the patients as well as their rights. Once the patients have agreed to participate in the study, they were requested to sign a consent form and a questionnaire comprised of demographic information of the patients, clinical and health related questions as well as socio economic questions was completed through an interview.

\section{Sample Collection}

Urine samples were collected using a wide mouthed container and transported in cooler boxes filled with ice, to the laboratory of Microbiology at the University of Venda. All specimens were properly labelled with patient's code and date of collection. The specimens were transported to the laboratory within $4 \mathrm{~h}$ of passing for further analysis.

\section{DNA Extraction}

Once in the laboratory, the urine samples were centrifuged at $6000 \mathrm{rpm}$ for $10 \mathrm{~min}$. The pellets were used for DNA purification. Extraction of the viruses genomic DNA from urine specimens was done using the GenElute Blood Genomic DNA Kit (Sigma-Aldrich, Germany) according to the manufacturer's instructions. The DNA was kept frozen at $-20^{\circ} \mathrm{C}$ until processing.

\section{Real-Time PCR}

Genomic DNA extracted from samples was used in a real-time PCR protocol with primers previously described (Markoulatos et al., 2001) with SYBR-Green-490 (Roche Diagnostics). For the detection of HSV1, a section of the long repeat (RL 2) region was targeted, while for HVS2, the long unique (UL 28) region in the genome of herpes simplex virus type 2 (HSV-2) was targeted by the primers. The reaction was performed in the light cycler 480 from Roche Diagnostics. The results were analysed with a userdefined threshold of 200 PCR Baseline Subtracted Curve-fit Relative Fluorescence Units (CF RFU). The level of positivity of the samples was then indicated by the Cycle Threshold (CT) values, which represent the number of cycles necessary for the samples to cross the threshold: the smaller it is, the more DNA there is in the samples.

Statistical analysis: The results of the study were analysed using the Statistical Package for Social Sciences (SPSS) software, version 19.0. The chi square $\left(\chi^{2}\right)$ test was used to determine the potential association between different demographic characteristics of the patients who provided the samples and HSV infections as well as other parameters such as clinical characteristics of the patients. The difference was considered significant when the $\mathrm{P}$ value was $<0.05$.

\section{Results}

\section{Real time PCR Detection of HSV1 and HSV2}

The amplification of the viruses HSV1 and HSV2 was conducted using the real time PCR. Following a number of run, a positive sample was used as a positive control while at every time at least two negative controls were used in order to make sure that the tests were specific and sensitive. The graphs in Fig. 1A-1D show examples of the amplification curves as well as the melting curves obtained from the light cycler 480 II showing the curves from the positive samples while the negative samples did not show any curves. 


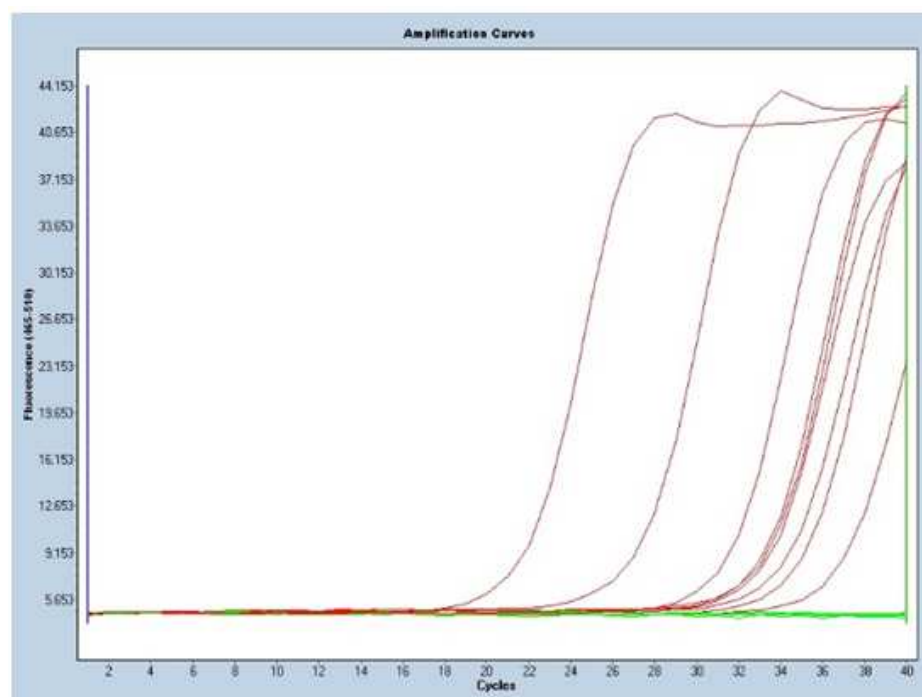

(A)

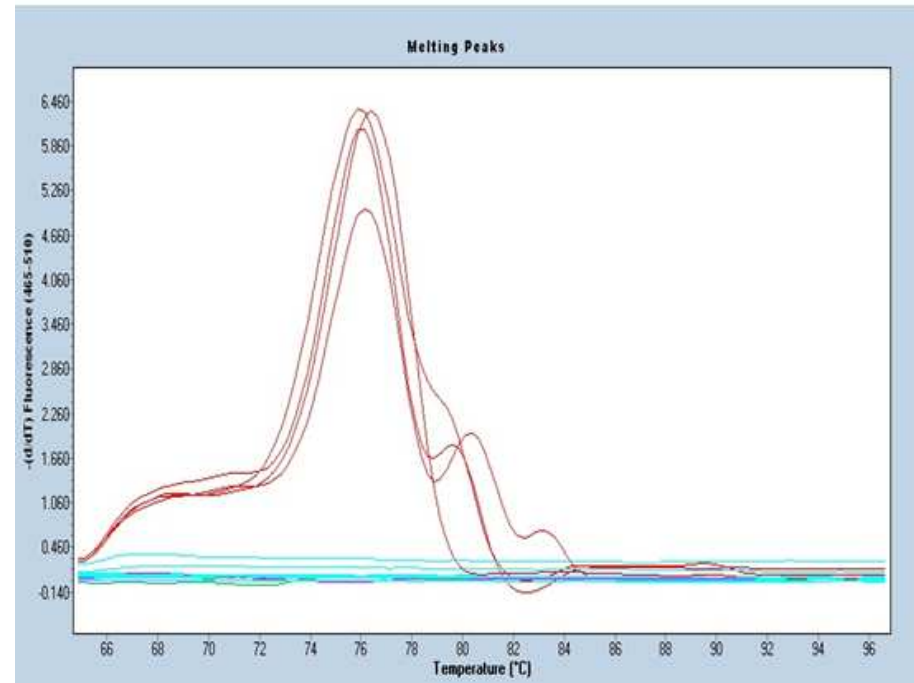

(B)

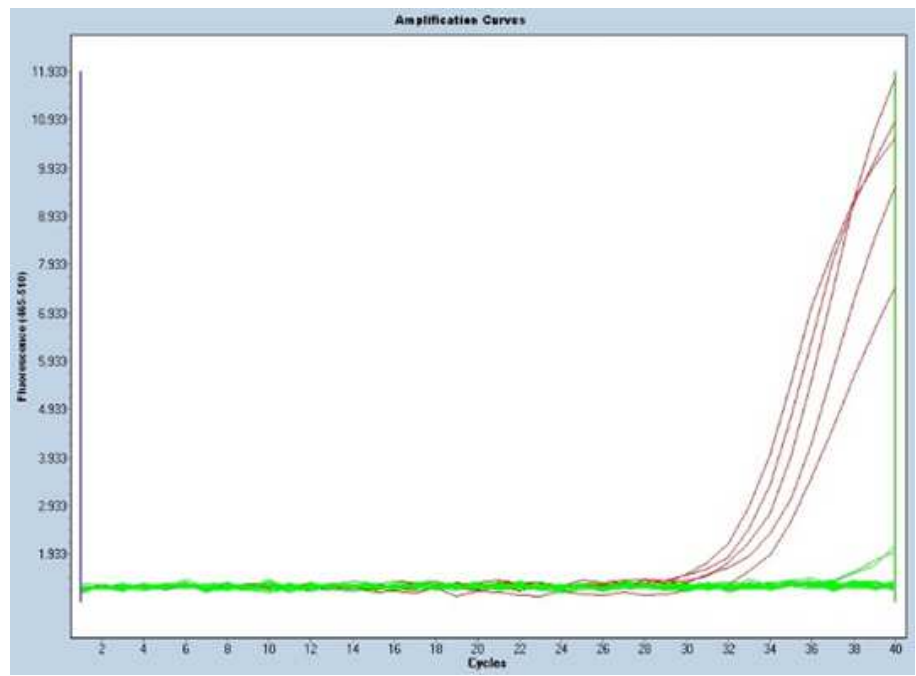

(C) 


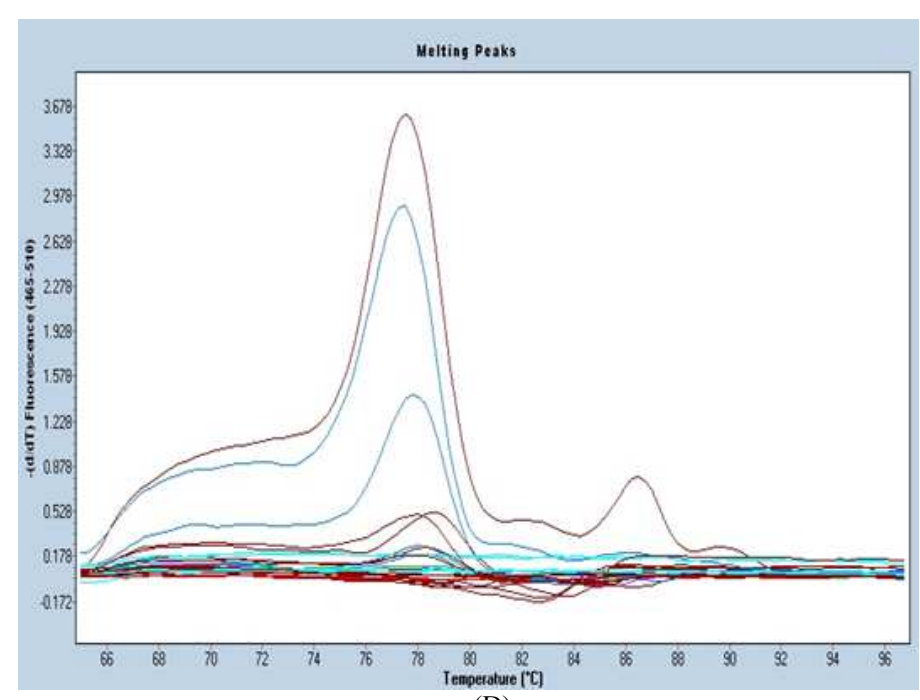

(D)

Fig. 1. Amplification curves of HSV1 (A) and HSV2 (C) and the melt curves for HSV1 (B) and HSV2 (D) obtained from the light cycler 480 II. On the amplification curves, the negative samples show flat curves similar to that of negative controls

\section{Demographic Characteristics of the Study Population}

A total of 308 samples were collected from the study participants of these, 217 (71.9\%) were females while 85 (28.1\%) were males of all the patients $117(38.2 \%)$ were married, while $20(6.5 \%)$ were divorced. The age of the patients varied from 1 to 75 years old with the mean age at $38.2 \pm 12.8$ years. They were grouped into 3 age groups and most of the patients were aged between $26-45$ years old $(59.6 \%)$ of the 308 participants, 102 (36.3\%) indicated that they kept animals in their households of these 61 (29.1\%) kept chicken, while only $10 \quad(3.5 \%)$ had cats. These demographic characteristics are recorded in Table 1.

\section{The Prevalence of HSV Infections in the Study Population}

HSV-1 was found to be more prevalent in males (51.8\%) compared to females $(47.0 \%)$, while HSV-2 prevalence was similar in females $(10.8 \%)$ and males $(10.6 \%)$. HSV-1 was more common in patients aged above $45(54.4 \%)(p=0.432)$. Individuals who were divorced had the highest prevalence of HSV-1 (57.9\%) while HSV-2 was more prevalent among the widows (17.9\%). HSV-2 prevalence was $40.0 \%$ in patients who got infected in Zimbabwe. In patients who got infected in Mopani District, the prevalence of HSV-1 was 83.3\% and the difference was not significant $(\mathrm{p}=0.394)$. The results are recorded in Table 2. Although overall there was association between HSV and CD4 count, HSV1 prevalence was significantly lower among patients with CD4 counts between 200 and 500 cells $/ \mathrm{cm}^{3}$ while individuals with CD4 count higher than $500 \mathrm{cell} / \mathrm{cm}^{3}$ had significantly higher prevalence of HSV.
Table 1. Demographic characteristics of the study population and animal ownership among patients

\begin{tabular}{|c|c|c|c|}
\hline \multicolumn{2}{|l|}{ Characteristics } & \multicolumn{2}{|c|}{ Frequency } \\
\hline \multirow[t]{2}{*}{ Sex } & Female & 85 & 28.1 \\
\hline & Male & 217 & 71.9 \\
\hline \multirow[t]{5}{*}{ Sample origin } & Donald Fraser & 166 & 53.9 \\
\hline & Elim & 52 & 16.9 \\
\hline & Tshakuma & 3 & 1.0 \\
\hline & Tshilidzini & 73 & 23.7 \\
\hline & University students & 14 & 4.5 \\
\hline \multirow[t]{4}{*}{ Marital status } & Single & 130 & 42.5 \\
\hline & Married & 117 & 38.2 \\
\hline & Divorced & 20 & 6.5 \\
\hline & Widow & 39 & 12.7 \\
\hline \multirow[t]{3}{*}{ Age group } & $<25$ & 31 & 10.5 \\
\hline & $26-45$ & 174 & 59.6 \\
\hline & $>45$ & 91 & 30.7 \\
\hline Animals in the house & Yes & 102 & 36.3 \\
\hline \multirow[t]{5}{*}{ Type of animals } & Chicken & 61 & 29.1 \\
\hline & Cattle & 21 & 7.3 \\
\hline & Dogs & 38 & 13.1 \\
\hline & Cats & 10 & 3.5 \\
\hline & Goats & 32 & 11.1 \\
\hline
\end{tabular}

The Relationship between the Prevalence of HSV Infections and the Clinical Presentation of the Patients

The prevalence of HSV-1 was very high in patients who did not have any skin infections (55.3\%) compared to those who did and the difference was significant $(p=0.005)$. HSV-1 and HSV-2 were found to be more prevalent in patients who were currently having genital warts (54.5 and $11.4 \%$ respectively) than those who were not and the difference was not significant. Patients who were coughing had an HSV-2 prevalence of 22.7 while $8.5 \%$ was obtained among those who were not coughing $(\mathrm{p}=0.031)$. 
Table 2. The prevalence of HSV infections in the study population and its association with different characteristics of the patients including immunologic and virologic characteristics of the participants

\begin{tabular}{|c|c|c|c|c|c|}
\hline Characteristics of the population & & HSV-1 (\%) & Statistics & HSV-2 & Statistics \\
\hline \multirow[t]{2}{*}{ Sex } & Male & $44(51.8)$ & $\chi^{2}=0.55 ; p=0.457$ & $9(10.6 \%)$ & $\chi^{2}=0.01 ; p=0.955$ \\
\hline & Female & $102(47.0)$ & & $24(10.8 \%)$ & \\
\hline \multirow[t]{3}{*}{ Age group } & $0-25$ & $14(43.8)$ & $\chi^{2}=1.67 ; p=0.432$ & $2(6.5 \%)$ & $\chi^{2}=1.08 ; p=0.582$ \\
\hline & $26-45$ & $80(47.1)$ & & $19(10.9 \%)$ & \\
\hline & $>45$ & $49(54.4)$ & & $12(13.2 \%)$ & \\
\hline \multirow[t]{4}{*}{ Marital status } & Divorced & $11(57.9)$ & $\chi^{2}=2.67 ; p=0.446$ & 0 & $\chi^{2}=4.81 ; p=0.186$ \\
\hline & Married & $60(51.3)$ & & $11(9.4 \%)$ & \\
\hline & Single & $55(43.3)$ & & $15(11.5 \%)$ & \\
\hline & Widowed & $20(52.6)$ & & $7(17.9 \%)$ & \\
\hline \multirow[t]{5}{*}{ Place of infection } & Gauteng & $12(60.0)$ & $\chi^{2}=5.18 ; p=0.394$ & $2(9.5 \%)$ & $\chi^{2}=7.52 ; p=0.185$ \\
\hline & Mopani & $5(83.3)$ & & $1(16.7 \%)$ & \\
\hline & Mpumalanga & $2(50.0)$ & & $1(25.0 \%)$ & \\
\hline & Vhembe & $119(47.2)$ & & $27(10.5 \%)$ & \\
\hline & Zimbabwe & $3(60.0)$ & & $2(40.0 \%)$ & \\
\hline \multirow[t]{5}{*}{ CD4 count range } & 0 to 50 cells & $17(41.5)$ & $\chi^{2}=1.29 ; p=0.256$ & $3(7.1 \%)$ & $\chi^{2}=0.73 ; p=0.39$ \\
\hline & 51 to 200 cells & $56(54.9)$ & $\chi^{2}=1.82 ; p=0.177$ & $13(12.5 \%)$ & $\chi^{2}=0.41 ; p=0.520$ \\
\hline & 201 to 500 cells & $37(40.2)$ & $\chi^{2}=4.94 ; p=0.026$ & $10(10.9 \%)$ & $\chi^{2}=0.001 ; p=0.976$ \\
\hline & 501 to 2500 cells & $24(68.6)$ & $\chi^{2}=5.77 ; p=0.016$ & $4(11.1 \%)$ & $\chi^{2}=0.001 ; p=0.973$ \\
\hline & Total & $134(49.6)$ & & $30(10.9 \%)$ & \\
\hline \multirow[t]{2}{*}{ HIV Viral load } & High (detectable) & $17(41.5)$ & $\chi^{2}=2.57 ; p=0.109$ & $8(18.2 \%)$ & $\chi^{2}=395 ; p=0.530$ \\
\hline & Low (Non detectable) & $27(58.7)$ & & $6(13.3 \%)$ & \\
\hline
\end{tabular}

Table 3. Prevalence of HSV infections according to clinical presentation of the patients

\begin{tabular}{|c|c|c|c|c|c|}
\hline Characteristics & & HSV-1 (\%) & Statistics & HSV-2 (\%) & Statistics \\
\hline \multirow[t]{2}{*}{ Skin infections } & No & $115(55.3)$ & $\chi^{2}=8.01 ; p=0.005$ & $20(9.3)$ & $\chi^{2}=0.212 ; p=0.645$ \\
\hline & Yes & $14(31.8)$ & & $5(11.6)$ & \\
\hline \multirow[t]{2}{*}{ Genital warts } & No & $124(47.3)$ & $\chi^{2}=4.12 ; p=0.043$ & $31(11.7)$ & $\chi^{2}=0.63 ; p=0.428$ \\
\hline & Yes & $13(72.2)$ & & $1(5.6)$ & \\
\hline \multirow[t]{2}{*}{ Sore on lips } & No & $121(47.6)$ & $\chi^{2}=0.48 ; p=0.487$ & $26(10.0)$ & $\chi^{2}=0.89 ; p=0.346$ \\
\hline & Yes & $26(53.1)$ & & $7(14.6)$ & \\
\hline \multirow[t]{2}{*}{ Fever } & No & $73(49.3)$ & $\chi^{2}=1.81 ; p=0.179$ & $15(9.9)$ & $\chi^{2}=0.27 ; p=0.602$ \\
\hline & Yes & $38(59.4)$ & & $5(7.7)$ & \\
\hline \multirow[t]{2}{*}{ Weakness and fatigue } & No & $120(51.3)$ & $\chi^{2}=0.01 ; p=0.916$ & $47(19.8)$ & $\chi^{2}=0.01 ; p=0.966$ \\
\hline & Yes & $9(50.0)$ & & $4(20.0)$ & \\
\hline \multirow[t]{2}{*}{ Coughing } & No & $118(51.3)$ & $\chi^{2}=0.01 ; p=0.907$ & $20(8.5)$ & $\chi^{2}=4.63 ; p=0.031$ \\
\hline & Yes & $11(50.0)$ & & $5(22.7)$ & \\
\hline \multirow[t]{2}{*}{ Mouth thrush } & No & $119(46.7)$ & $\chi^{2}=2.21 ; p=0.138$ & $27(10.4)$ & $\chi^{2}=0.13 ; p=0.706$ \\
\hline & Yes & $28(58.3)$ & & $6(10.4)$ & \\
\hline \multirow[t]{2}{*}{ Pain } & No & $107(49.3)$ & $\chi^{2}=2.21 ; p=0.137$ & $20(9.0)$ & $\chi^{2}=0.96 ; p=0.328$ \\
\hline & Yes & $22(62.8)$ & & $5(14.3)$ & \\
\hline \multirow[t]{2}{*}{ Shortness of breath } & No & $94(50.3)$ & $\chi^{2}=2.71 ; p=0.100$ & $15(7.9)$ & $\chi^{2}=1.29 ; p=0.285$ \\
\hline & Yes & $27(64.3)$ & & $6(13.3)$ & \\
\hline \multirow[t]{2}{*}{ TB } & No & $95(46.3)$ & $\chi^{2}=9.13 ; p=0.003$ & $25(12)$ & $\chi^{2}=0.07 ; p=0.791$ \\
\hline & Yes & $17(81)$ & & $2(10)$ & \\
\hline
\end{tabular}

In patients who were HIV positive, an HSV-1 prevalence of $49.3 \%$ was obtained while $22.2 \%$ was obtained among HIV negative patients $(\mathrm{p}=0.109)$. Similarly, Tuberculosis (TB) as well as genital warts were significantly associated with HSV1 and not HSV2 $(\mathrm{p}<0.05)$. The results are shown in Table 3 .

The Relationship between the Prevalence of HSV Infections and Socioeconomic Conditions and Animals Ownership among the Study Participants

Animals in the houses of the patients were somehow associated with HSV infection, both HSV-1 and HSV-2 were found to be more prevalent among patients who lived in houses with animals compared to those without animals and the difference was significant for HSV-2 $(p=0.033)$ but not significant for HSV-1 $(p=0.946)$. Chickens and cattle were mostly associated with the presence of HSV-1 (47.5 and 52.4\%), although the difference was not significant. However, HSV-2 was significantly prevalent ( $p$ $=0.025$ ) in patients who had cattle in their houses. Cats and goats were mostly associated with HSV-1 but the difference was not significant. HSV-1 infections was more common among dog owners but the difference was not significant $(\mathrm{p}=0.417)$ and HSV-2 was significantly present $(\mathrm{p}=$ 0.024 ) in patients who had dogs in their houses. The socioeconomic conditions of the patients were not associated with the prevalence of HSV among the participants. The results are recorded in Table 4. 
Table 4. Prevalence of HSV infections according to socioeconomic condition and animal ownership among HIV patients in Northern South Africa

\begin{tabular}{|c|c|c|c|c|c|}
\hline Characteristics & HSV-1 & Statistics & HSV-2 & Statistics & \\
\hline \multirow[t]{2}{*}{ Animals in the house } & No & $87(48.6 \%)$ & $\chi^{2}=0.01 ; p=0.946$ & $14(7.6 \%)$ & $\chi^{2}=4.56 ; p=0.033$ \\
\hline & Yes & $50(49.0 \%)$ & & $16(15.7 \%)$ & \\
\hline \multirow[t]{5}{*}{ Type of animals } & Chickens & $29(47.5 \%)$ & $\chi^{2}=0.08 ; p=0.779$ & $9(15.0 \%)$ & $\chi^{2}=1.59 ; p=0.208$ \\
\hline & Cattle & $11(52.4 \%)$ & $\chi^{2}=0.10 ; p=0.757$ & $2(9.5 \%)$ & $\chi^{2}=0.02 ; p=0.874$ \\
\hline & Dogs & $21(55.3 \%)$ & $\chi^{2}=0.66 ; p=0.417$ & $8(21.1 \%)$ & $\chi^{2}=511 ; p=0.024$ \\
\hline & Cats & $5(50.0 \%)$ & $\chi^{2}=0.01 ; p=0.956$ & $1(11.1 \%)$ & $\chi^{2}=0.01 ; p=0.955$ \\
\hline & Goats & $15(46.9 \%)$ & $\chi^{2}=0.07 ; p=0.786$ & $5(15.6 \%)$ & $\chi^{2}=0.983 ; p=0.322$ \\
\hline Income less than & No & $69(53.1 \%)$ & $\chi^{2}=0.03 p=0.852$ & $13(9.9 \%)$ & $\chi^{2}=0.48 ; p=0.489$ \\
\hline R1000 ( USD70) & Yes & $50(54.3 \%)$ & & $7(7.3 \%)$ & \\
\hline \multirow[t]{5}{*}{ Dependents } & No dependents & $6(33.3 \%)$ & $\chi^{2}=7.48 ; p=0.113$ & $4(22.2 \%)$ & $\chi^{2}=9.05 ; p=0.060$ \\
\hline & 1 to 3 dependents & $50(45.5 \%)$ & & $7(6.2 \%)$ & \\
\hline & 4 to 6 dependents & $54(46.6 \%)$ & & $19(16.1 \%)$ & \\
\hline & 7 to 9 dependents & $23(67.6 \%)$ & & $2(5.9 \%)$ & \\
\hline & 10 or more dependents & $3(60 \%)$ & & $1(20 \%)$ & \\
\hline \multirow[t]{4}{*}{ Education } & No education & $17(50 \%)$ & $\chi^{2}=0.73 ; p=0.866$ & $5(14.7 \%)$ & $\chi^{2}=2.04, p=0.564$ \\
\hline & Primary education & $42(52.5 \%)$ & & $6(7.4 \%)$ & \\
\hline & Secondary education & $70(47 \%)$ & & $19(12.4 \%)$ & \\
\hline & Some tertiary education & $12(52.2 \%)$ & & $2(8.3 \%)$ & \\
\hline
\end{tabular}

Table 5. The prevalence of HSV infections according the current ARV regimen used by the patients

\begin{tabular}{|c|c|c|c|c|c|}
\hline \multicolumn{2}{|l|}{ ARV regimen } & HSV1 $(\%)$ & Statistics & HSV2 (\%) & Statistics \\
\hline \multicolumn{2}{|l|}{ Efavirenz, lamivudine, stavudine } & $45(57)$ & $\chi^{2}=1.25 ; p=0.262$ & $10(12)$ & $\chi^{2}=0.079 ; p=0.778$ \\
\hline \multicolumn{2}{|l|}{ Efavirenz, lamivudine, tenofovir } & $18(52.9)$ & $\chi^{2}=0.006 ; p=0.938$ & $2(6.1)$ & $\chi^{2}=1.65 ; p=0.198$ \\
\hline \multicolumn{2}{|l|}{ Efavirenz, lamivudine, zidovudine } & $8(33.3)$ & $\chi^{2}=4.053 ; p=0.044$ & $8(34.8)$ & $\chi^{2}=11.512 ; p=0.001$ \\
\hline \multicolumn{2}{|l|}{ Lamivudine, nevirapine, stavudine } & $14(56)$ & $\chi^{2}=0.156 ; p=0.693$ & $1(4)$ & $\chi^{2}=2.026 ; p=0.155$ \\
\hline \multicolumn{2}{|l|}{ Others ARV combinations } & $4(50)$ & $\chi^{2}=0.019 ; p=0.891$ & $1(12.5)$ & $\chi^{2}=0.001 ; p=0.980$ \\
\hline \multirow[t]{2}{*}{ Zidovudine } & No & $76(55.9)$ & $\chi^{2}=3.39 ; p=0.065$ & $13(9.4)$ & $\chi^{2}=7.68 ; p=0.006$ \\
\hline & Yes & $13(38.2)$ & & $9(27.3)$ & \\
\hline \multirow[t]{2}{*}{ Efavirenz } & No & $16(53.3)$ & $\chi^{2}=0.01 ; p=0.906$ & $1(3.3)$ & $\chi^{2}=2.914 ; p=0.088$ \\
\hline & Yes & $73(52.1)$ & & $21(14.8)$ & \\
\hline \multirow[t]{2}{*}{ Lamivudine } & No & $4(66.7)$ & $\chi^{2}=0.51 ; p=0.475$ & $1(16.7)$ & $\chi^{2}=0.08 ; p=0.772$ \\
\hline & Yes & $85(51.8)$ & & $21(12.7)$ & \\
\hline \multirow[t]{2}{*}{ Tenofovir } & No & $65(51.6)$ & $\chi^{2}=0.114 ; p=0.735$ & $19(14.7)$ & $\chi^{2}=1.74 ; p=0.187$ \\
\hline & Yes & $24(54.5)$ & & $3(7.0)$ & \\
\hline \multirow[t]{2}{*}{ Nevirapine } & No & $74(51.4)$ & $\chi^{2}=0.35 ; p=0.554$ & $22(15.1)$ & $\chi^{2}=4.492 ; p=0.034$ \\
\hline & Yes & $15(57.7)$ & & $0(0)$ & \\
\hline \multirow[t]{2}{*}{ Stavudine } & No & $34(45.3)$ & $\chi^{2}=2.65 ; p=0.103$ & $10(13.7)$ & $\chi^{2}=0.09 ; p=0.759$ \\
\hline & Yes & $55(57.9)$ & & $12(12.1)$ & \\
\hline \multirow[t]{2}{*}{ Taking antiretrovirals (ARV) } & No & $40(42.6)$ & $\chi^{2}=2.53 ; p=0.112$ & $9(9.3)$ & $\chi^{2}=0.45 ; p=0.501$ \\
\hline & Yes & $105(52.5)$ & & $24(11.9)$ & \\
\hline \multirow[t]{4}{*}{ Time to treatment } & 1 & $61(55)$ & $\chi^{2}=1.08 ; p=0.781$ & $10(8.7)$ & $\chi^{2}=8.55 ; p=0.036$ \\
\hline & 2 & $26(48.1)$ & & $5(9.3)$ & \\
\hline & 3 & $12(46.2)$ & & 7 (26.9) & \\
\hline & 4 & $7(53.8)$ & & $3(23.1)$ & \\
\hline \multirow[t]{4}{*}{ Time since HIV positive } & 1 & $52(48.1)$ & $\chi^{2}=1.67 ; p=0.644$ & $9(8.1)$ & $\chi^{2}=4.564 ; p=0.207$ \\
\hline & 2 & $40(44.9)$ & & $10(11.1)$ & \\
\hline & 3 & $32(54.2)$ & & $6(10)$ & \\
\hline & 4 & $18(54.5)$ & & $7(21.3)$ & \\
\hline
\end{tabular}

The Prevalence of HSV Infections and the Current Antiretroviral Drug (ARV) Regimen used by the Patients

The prevalence of HSV infection seemed to be modulated by the current ARV regimen used by patients. Patients who were not taking zidovudine had a high prevalence of HSV-1 (55.9\%) compared to those who did (38.2\%), although the difference was not statistically significant $(\mathrm{p}=0.065)$. However, HSV-2 was significantly prevalent $(p=0.006)$ in patients who were taking zidovudine $(27.3 \%)$ than those who did not $(9.4 \%)$. Patients who were not taking efavirenz and lamivudine had a higher HSV-1 (53.3 and 66.7\%, respectively) compared to those who were taking these drugs but the difference was not statistically significant. HSV-2 was significantly prevalent $(\mathrm{p}=0.034)$ in patients who were not taking nevirapine $(15.1 \%)$. The results are recorded in Table 5. 


\begin{tabular}{|c|c|c|c|c|c|}
\hline Characteristics & & HSV-1 (\%) & Statistics & HSV-2 (\%) & Statistics \\
\hline \multirow[t]{5}{*}{ Age at first sex } & 12 to 15 years & $6(33.3)$ & \multirow{5}{*}{$\chi^{2}=4.38 ; p=0.357$} & $4(23.5)$ & \multirow{5}{*}{$\chi^{2}=4.54 ; p=0.338$} \\
\hline & 16 to 18 years & $66(53.7)$ & & $13(10.3)$ & \\
\hline & 19 to 22 years & $43(46.7)$ & & $7(7.2)$ & \\
\hline & 23 to 25 years & $8(36.4)$ & & $2(10.0)$ & \\
\hline & $>25$ years & $3(50.0)$ & & $1(16.7)$ & \\
\hline \multirow[t]{3}{*}{ Number of partners since first sex } & $1-4$ partners & $72(51.1)$ & \multirow[t]{3}{*}{$\chi^{2}=1.39 ; p=0.499$} & $12(8.4)$ & \multirow[t]{3}{*}{$\chi^{2}=0.90 ; p=0.637$} \\
\hline & 5-9 partners & $27(42.2)$ & & $8(12.3)$ & \\
\hline & $>10$ partners & $25(48.1)$ & & $6(11.3)$ & \\
\hline \multirow[t]{2}{*}{ Abstaining from sex } & No & $83(49.1)$ & \multirow[t]{2}{*}{$\chi^{2}=0.02 ; p=0.890$} & $19(10.9)$ & \multirow[t]{2}{*}{$\chi^{2}=0.01 ; p=0.916$} \\
\hline & Yes & $48(50.0)$ & & $11(11.3)$ & \\
\hline \multirow[t]{2}{*}{ Condom use } & No & $63(52.1)$ & \multirow[t]{2}{*}{$\chi^{2}=0.02 ; p=0.900$} & $11(8.9)$ & \multirow[t]{2}{*}{$\chi^{2}=0.01 ; p=0.950$} \\
\hline & Yes & $5(50.0)$ & & $1(8.3)$ & \\
\hline
\end{tabular}

\section{The Prevalence of HSV Infections and the Patients' Sexual Behavior}

Patients who had their first sex at the age of 16 to 18 years had a high prevalence of HSV-1 (53.7\%) and patients who had their first sex at the age of 12 to 15 years had a higher prevalence of HSV-2, although the difference was not statistically significant. HSV-1 was non-significantly prevalent in patients who had 1-4 partners since first sex $(51.1 \%)$ and patients who had 5-9 partners since first sex had high prevalence of HSV-2 $(12.3 \%)$ although the difference was not significant. Patients who claimed that they were abstaining from sex had a higher prevalence of both HSV-1 and HSV-2 but the difference was not significant. HSV-1 and HSV-2 were non-significantly present in patients who were not using condoms. The results are recorded in Table 6 .

\section{Discussion}

Infections caused by Herpes Simplex Virus type 1 and 2 (HSV-1 and HSV-2) are associated with substantial morbidity, transmission and acquisition of the Human Immunodeficiency Virus (HIV) (Weiss et al., 2016). Over two-thirds of individuals infected are unaware of their infections and the majority of infections are transmitted by these individuals (Schulte et al., 2016). HSV-1 is the primary cause of oral-labial herpes and is even more common, with an estimated sero-prevalence of close to $90 \%$ in many nations (Bernstein et al., 2012). However, the epidemiology of HSV-1 is changing, such that the frequency of sexual transmission of HSV-1 has increased in many countries (Ryder et al., 2009). HSV-2 is a sexually transmitted pathogen that causes genital infection and infects more than 500 million people worldwide (David and Emmert, 2012). The present study found a high prevalence of HSV-1 from urine samples compared to HSV-2 (48.3 and $10.7 \%$, respectively) when real-time PCR assay was used. A study conducted in Soweto, South Africa showed that $17 \%$ of pregnant women shed HSV2 (Perti et al., 2014). Similarly, studies conducted in South West of Iran showed that the HSV-1 sero-prevalence $(79.2 \%)$ was higher than HSV-2 (23.3\%) (Tayyebi and Sharifi, 2010). In a study conducted in Maryland, Mark et al. (2007) obtained an HSV-1 and HSV-2 sero-prevalence of 48 and 3.4\% respectively by Western Blot assay. Epidemiologic studies conducted among miners and commercial sex workers in South Africa reported sero-prevalence rates of $60-90 \%$ respectively (Auvert et al., 2001). However, very few studies to our knowledge have investigated the occurrence of HSV in South Africa using a direct methods for the detection of the virus itself. HSV-1 was isolated from $11 \%$ of patients suffering from keratitis in a recent study in South Africa among HIV patients (Schaftenaar et al., 2016), further indicating the importance of screening for HSV-1 in communities with high HIV prevalence.

Gender distribution of sexually transmitted infections need to be well understood as it might have a significant impact on the measures to be taken for the control of the disease. Agabi et al. (2010) found an HSV-2 seroprevalence of $92.8 \%$ among males and $86.4 \%$ among females who were attending sexually transmitted infections clinic in Jos, Nigeria where an HSV-2 type specific IgG EIA test kit was used. In a study conducted in Brazil, the sero-prevalence of HSV-2 was found to be higher in males (53\%) than females $(50.7 \%)$ (Santos et al., 2006). In the present study, similar results were found showing similar prevalence of HSV-2 of $10.6 \%$ in males and $10.8 \%$ in females using real time PCR. However, In Kenya, Mugo et al. (2011) found a seroprevalence of $26 \%$ among males and $42 \%$ among females. In the present study the prevalence of HSV-1 was found to be $51.8 \%$ in males and $47 \%$ in females. The present study also found that there were some association between animal ownership and HSV infections. Although there is no clear evidence of HSV transmission between animal and Humans, pet or animal ownership in general could be associated with a certain level of luxury life or like in the case of dogs, a certain degree of freedom and a potential increase in the night life brought about by the security provided by the presence of the dog. However these 
are only assumptions since there has been no definitive links between animal ownership and HSV infections. Although animals are known to be infected with HSV there has not been any definitive case of zoonotic HSV transmission (Quattrocchi et al., 2017; Laval et al., 2016).

The prevalence of HSV-1 and HSV-2 also varies with marital status of study participants. Often, married people are considered to be low risk. However, in our study, patients who were married had a higher prevalence of HSV-1 (51.3\%) compared to those who were single $(43.3 \%)$. For HSV-2 a prevalence of $9.4 \%$ was obtained in married patients while $11.5 \%$ was found in patients who were single. In a study conducted in Nigeria, $86.2 \%$ of HSV-2 was found in married patients and $89.1 \%$ in single patients (Agabi et al., 2010). In a study to determine the HSV-2 sero-positivity and relationship status among U.S. adults aged between 20 and 40, those who were un-partnered had higher HSV-2 prevalence than those who were married. Among the unpartnered aged 45 to 49 years, a sero-prevalence of $55.3 \%$ in women and $25.7 \%$ in men was reported (Bauer et al., 2010). In a study conducted in Zimbabwe, the prevalence of HSV-2 among married patients was 49.4 and $28.6 \%$ in patients who were single (Bauer et al., 2010).

In order to evaluate any potential association between the occurrence of HSV and other symptoms described among the HIV patients, we enquired about these conditions among our study participants. The prevalence of HSV-1 and 2 in patients who experienced fever was 59.4 and $7.7 \%$ respectively, although the difference was not significant. The results were similar to those in a study conducted by Bernstein et al. (2012), who also found a non-significantly higher prevalence of HSV-1 and HSV-2 in patients who had fever (17.9 and 33.3\% respectively). In the same study done by Bernstein et al. (2012) in America, the prevalence of HSV-1 was 3.6\% in patients with genital warts which was very low compared to the present study in which $54.5 \%$ of HSV-1 patients also had genital warts. In Tanzania, Msuya et al. (2009) obtained a prevalence of $1.1 \%$ in HIV positive patients who had genital warts (Munjoma et al., 2010).

Different methodological approaches may have different significance. Generally studies conducted using antibody detection give an idea on the exposure level in the study set up while the detection of the pathogenic agent by real time Polymerase Chain Reaction (PCR) might give an indication of the current shedding rate of the pathogen. In a study conducted in the Venda region South Africa, Bessong and Mathomu (2010) found an HSV $1 / 2$ prevalence of $86.2 \%$ in males and $81.6 \%$ in female patients who were HIV positive by HSV-1/2 IgG antibodies (Bessong and Mathomu, 2010). This indicates high exposure rates of HSV $1 / 2$ on the study population. The level of infection with HSV could also vary according to the HIV status of the study participants. In a study to determine the epidemiology of genital infection with HSV-1 and HSV-2 genitourinary medicine attendees in inner London by real time PCR, the prevalence of HSV was $74 \%$ among HIV positive patients and $61 \%$ among HIV negative patients (Ramaswamy et al., 2005). A longitudinal study in Orange Farm, South Africa, Sobngwi-Tambekou et al. (2009) found an HSV-2 prevalence of $13.6 \%$ among HIV positive young men using HSV-2 type specific IgG assay. In Durban, South Africa, a study was conducted to determine whether HSV-2 infection was a risk factor for HIV sero-conversion using ELISA found a significantly high prevalence of HSV-2 (84\%) among HIV positive patients (Ramjee et al., 2002).

Sexual behaviour can often modulate the acquisition and prevalence of sexually transmitted infections such as HSV. In a study conducted in Coastal Peru, HSV-2 was significantly prevalent in female patients who had more than 10 sexual partners $(21.1 \%)$ (Konda et al., 2005). In the present study HSV-2 was prevalent in patients who had more than 10 sexual partners (11.3\%). Previous studies similarly showed that, the prevalence of HSV-2 was significantly high in patients who were not using condoms during sexual intercourse (23.5\%) (Rosenberg et al., 2015). Serological testing showed that patients who used condoms (85\%) has a higher HSV-2 prevalence than those who were not using protection (80\%) (Agabi et al., 2010). These results were similar to those of the present study in which patients who were using protection had a higher HSV-2 prevalence than those who were not using protection, although the difference was not significant. The reason for this might be because patients were already infected when they started to use protection. Some limitations of the present study were that the number of HIV negative patients was very small. This is because the primary objective of the study was to detect these pathogens among HIV infected patients who were initiating ARVs. Since the centres, used for patients' recruitment are also testing centres, only a limited numbers of HIV negative patients were encountered and were included in the study as well.

The present study was designed to determine the prevalence and potential risk factors of HSV among HIV patients in the northern region of South Africa where little data exist. Certain limitations have been noted such as the sample size. This was due to the difficulties in recruitment considering the stigma still associated with HIV in our communities. Furthermore data on the immunological and virologic characteristics of the patients were not complete.

\section{Conclusion}

The present study showed a higher prevalence of HSV-1 compared to HSV-2 in urine samples obtained from HIV and AIDS patients in the Limpopo Province. Surprisingly, coughing and animal ownership among patients particularly those who had dogs were identified 
as risk factors that could contribute to infection with HSV-2. Educational messages should also be addressed at the community in large, in order to seek help early for the treatment of STIs. The detection of HSV from urine samples using real time PCR could be a good alternative method for diagnosing HSV infection because of its ease of application and urine is a non-invasive sample. However, additional studies are required using larger sample size in order to confirm these hypotheses.

\section{Acknowledgement}

The authors would like to acknowledge the study participants and National Research Foundation of South Africa for funding.

\section{Authors' Contribution}

Amidou Samie: Designed the study, carried out sample collection, Real Time PCR and data analysis.

Hlayisani Preclude Mnisi: Drafted the manuscript and participated in data analysis and reviewed for important content.

Mary Noluthando Ramantswana: Purified DNA and prepared the samples for real time PCR.

\section{Competing Interest}

The authors declare that they have no competing interest.

\section{References}

Agabi, Y.A., E.B. Banwat, J.D. Mawak, P.M. Lar and N. Dashe et al., 2010. Seroprevalence of herpes simplex virus type- 2 among patients attending the sexually transmitted infections clinic in Jos, Nigeria. J. Infect. Dis., 4: 572-575.

Aryee, E.A., R.L. Bailey, A. Natividad-Sancho, S. Kayeand and M.J. Holland, 2005. Detection, quantification and genotyping of herpes simplex virus in cervicovaginal secretions by real-time PCR: A cross sectional survey. Virol. J., 2: 61-71.

Auvert, B., R. Ballard, C. Campbell, M. Caraël and M. Carton et al., 2001. HIV infection among youth in South African mining town is associated with herpes simplex virus-2 seropositivity and sexual behaviour. AIDS, 15: 885-98.

Bauer, G.R., N. Khobzi and T.A. Coleman, 2010. Herpes simplex virus type 2 seropositivity and relationship status among U.S. adults age 20 to 49: a populationbased analysis. BMC Infect. Dis., 10: 359-359.

Bernstein, D.I., A.R. Bellamy, E.W. Hook, M.J. Levin and A. Wald et al., 2012. Epidemiology, clinical presentation and antibody response to primary infection with herpes simplex virus type 1 and type 2 in young women. Clin. Infect. Dis., 56: 344-351.
Bessong, P.O. and L.M. Mathomu, 2010. Seroprevalence of HTLV1/2, HSV1/2 and Toxoplasma gondii among chronic HIV-1 infected individuals in rural north eastern South Africa. Afr. J. Microbiol. Res., 4: 2587-2591.

David, H. and M.D. Emmert, 2012. Treatment of common cutaneous herpes simplex virus infections. Am. Fam. Phys., 61: 1697-1704.

Filén, F., A. Strand, A. Allard, J. Blomberg and B. Herrmann, 2004. Duplex real-time polymerase chain reaction assay for detection and quantification of herpes simplex virus type 1 and herpes simplex virus type 2 in genital and cutaneous lesions. Sex. Tran. Dis., 6: 331-336.

Garland, S.M. and M. Steben, 2015. Genital herpes. Best Pract. Res. Clin. Obstet. Gynaecol., 28: 1098-110.

Jewkes, R., M. Nduna, J. Levin, N. Jama and K. Dunkle et al., 2008. Impact of stepping stones on incidence of HIV and HSV-2 and sexual behaviour in rural South Africa: Cluster randomised controlled trial. Brit. Med. J., 337: 506-506.

Konda, K.A., J.D. Klausner, A.G. Lescano, S. Leon and F.R. Jones et al., 2005. The epidemiology of herpes simplex virus type 2 infection in lowincome urban populations in coastal Peru. Sex Transm. Dis.

Laval, K., J. Van Cleemput, K.C. Poelaert, I.K. Brown and H.J. Nauwynck, 2017. Replication of neurovirulent equine herpesvirus type 1 (EHV-1) in CD172a+monocytic cells. Comp. Immunol. Microbiol. Infect. Dis., 50: 58-62. DOI: $10.1016 /$ j.cimid.2016.11.006

Looker, K.J., A.S. Magaret, M.T. May, K.M. Turner and P. Vickerman et al., 2015. Global and regional estimates of prevalent and incident herpes simplex virus type 1 infection in 2012. PLoS One, 10: e0140765-e0140765.

Mark, H.D., J.P. Nanda, J. Roberts, A. Rompalo and J.H. Melendez et al., 2007. Performance of focus Elisa tests for HSV-1 and HSV-2 antibodies among university students with no history of genital herpes. Sex Transm. Dis., 34: 681-685.

Markoulatos, P., A. Georgopoulou, N. Siafakas, E. Plakokefalos and G. Tzanakaki et al., 2001. Laboratory diagnosis of common herpes infections of the central nervous system by multiplex PCR assay. J. Clin. Microbiol., 39: 4426-4432.

Msuya, S.E., J. Uriyo, A. Hussain, E.M. Mbizvo and S. Jeansson et al., 2009. Prevalence of sexually transmitted infections among pregnant women with known HIV status in northern Tanzania. Reproductive Health, 6: 1742-4755. 
Mugo, N., S.S. Dadabhai, R. Bunnell, J. Williamson and E. Bennett et al., 2011. Prevalence of herpes simplex virus type 2 infection, human immunodeficiency virus/herpes simplex virus type 2 coinfection and associated risk factors in a national, population-based survey in Kenya. Sex Transm. Dis., 38: 1059-1066.

Munjoma, M.W., E.N. Kurewa, M.P. Mapingure, G.V. Mashavave and M.Z. Chirenje et al., 2010. The prevalence, incidence and risk factors of herpes simplex virus type 2 infection among pregnant Zimbabwean women followed up nine months after birth. BMC Womens's Health, 10: 1472-6874.

Nag, S., S. Sarkar, D. Chattopadhyay, S. Bhattacharya and R. Biswas, 2015. Seroprevalence of herpes simplex virus infection in HIV coinfected individuals in eastern India with risk factor analysis. Adv. Virol., 2015: 537939-537939. DOI: 10.1155/2015/537939

Pandori, M.W., J. Lei, E.H. Wong, J. Klausner and S. Liska, 2006. Real-time PCR for detection of herpes simplex virus without nucleic acid extraction. BMC Inf. Dis., 6: 1471-2334.

Perti, T., M. Nyati, G. Gray, G. De Bruyn and S. Selke et al., 2014. Frequent genital HSV-2 shedding among women during Labor in Soweto, South Africa. Infect. Dis. Obstet. Gynecol. DOI: $10.1155 / 2014 / 258291$

Quattrocchi, V., I. Soria, C.A. Langellotti, V. Gnazzo and M. Gammella et al., 2017. A DNA vaccine formulated with chemical adjuvant provides partial protection against bovine herpes virus infection in cattle. Front Immunol., 8: 37-37. DOI: $10.3389 /$ fimmu. 2017.00037

Ramaswamy, M., C. Mcdonald, C. Sabin, C. TenantFlowers and M. Smith et al., 2005. The epidemiology of genital infection with herpes simplex virus types 1 and 2 in genitourinary medicine attendees in inner London. Sex Transm. Infect., 81: 306-308.

Ramjee, G., E. Gouws, E. Van Dyke, B. Williams and S.A. Karim, 2002. Herpes simplex virus type ii infection is a risk factor for HIV seroconversion. AIDS Bull., 11: 27-29.

Rezaei-Chaparpordi, S., M. Assmar, N. Amirmozafari, L. Modiri and A. Massiha et al., 2012. Seroepidemiology of HSV-1 and 2 in Anzali city 2010-2011. ZJRMS, 14: 67-69.

Rodrigues, D., F. De-Paris, R. Rodrigo and R.M. Paiva, 2013. Minimum detection limit of an in house nested PCR assay for HSV and varicella zoster virus. Rev. Soc. Bras. Med. Trop., 46: 625-628.

Rosenberg, M., A. Pettifor, A. Van Rie, H. Thirumurthy and M. Emch et al., 2015. The relationship between alcohol outlets, HIV risk behavior and HSV-2Infection among South African Young Women: A crosssectional study. PLoS One, 10: e0125510-e0125510.

Ryder, N., F. Jin, A.M. McNulty, A.E. Grulich and B. Donovan, 2009. Increasing role of herpes simplex virus type 1 in first-episode anogenital herpes in heterosexual women and younger men who have sex with men, 1992-2006. Sex Transm Infect., 85: 416-419.

Santos, F. and S.A. de Oliveira, S. Setúbal, L.A. Camacho and T. Faillace et al., 2006. Seroepidemiological study of herpes simplex virus type 2 in patients with the acquired immunodeficiency syndrome in the city of Niterói, Rio de Janeiro, Brazil. Mem. Inst. Oswaldo Cruz, 101: 315-319.

Schaftenaar, E., R.P. Peters, G.S. Baarsma, C. Meenken and N.S. Khosa et al., 2016. Clinical and corneal microbial profile of infectious keratitis in a high HIV prevalence setting in rural South Africa. Eur. J. Clin. Microbiol. Infect. Dis., 35: 1403-1409.

Schulte, J.M., A.R. Bellamy, E.W. Hook D.I. Bernstein and M.J. Levin et al., 2014. HSV-1 and HSV-2 seroprevalence in the united states among asymptomatic women unaware of any herpes simplex virus infection (Herpevac Trial for Women). South Afr. Med. J., 107: 79-84.

Sobngwi-Tambekou, J., D. Taljaard, P. Lissouba, K. Zarca and A. Puren et al., 2009. Effect of HSV-2 serostatus on acquisition of HIV by young men: Results of a longitudinal study in Orange Farm, South Africa. J. Infect. Dis., 199: 958-964. DOI: 10.1086/597208

Swenson, P.D., A. El-Sabaeny, V. Thomas-Moricz, M. Allen and A. Groskopf et al., 2016. Evaluation of a transcription mediated amplification assay for detection of herpes simplex virus types 1 and 2 mRNA in clinical specimens. J. Clin. Virol., 80: 62-67.

Tayyebi, D. and S. Sharifi, 2010. Seroepidemiology of infection with Herpes Simplex Virus types 1 and 2 (HSV1 and HSV2) among asymptomatic university students attending Islamic Azad University of Kazeroun, southwest of Iran. Iranian Clin. Infect. Dis., 5: 84-88.

Wang, G.C., C. Han, B. Detrick, V. Casolaro and D.M. Levine et al., 2016. Herpesvirus infections and risk of frailty and mortality in older women: Women's health and aging studies. J. Am. Geriatr Soc. DOI: 10.1111 jgs. 14090

Weiss, H.A., J. Vandepitte, J.N. Bukenya, Y. Mayanja and S. Nakubulwa et al., 2016. High levels of persistent problem drinking in women at high risk for HIV in Kampala, Uganda: A prospective cohort study. Int. J. Environ. Res. Pub. Health, 22: 153-153. DOI: 10.3390/ijerph13020153

Whitley, R.J. and B. Roizman, 2001. Herpes simplex virus infections. Lancet, 357: 1513-1518. 